\title{
Effect of step up exercise on cognitive attention with stroop test in Bengali male college students
}

\author{
Parthasarathi Debray', Susanta Biswas², Prasanta Biswas², Tapasi Saha1, Madhu Sudan Pal ${ }^{3}$ \\ ${ }^{1}$ Assistant Professor, Department of Human Physiology, N S Mahavidyalaya, Udaipur, Gomati District, Tripura, ${ }^{2}$ Guest Teacher, Department \\ of Human Physiology, N S Mahavidyalaya, Udaipur, Gomati District, Tripura, ${ }^{3}$ Scientist, Defence Institute of Physiology and Allied \\ Sciences (DIPAS), Luck now Road, Delhi
}

\section{A B STR A C T}

Introduction: A beneficial influence of exercise on cognitive and brain functions has been established. Exercise is drawing increasing research attention for improving neurocognitive functions. Aim: The aim of the present study is to examine the effect of step up exercise on mental attention with strop test in Bengali male college students. Methodology: Twenty eight (28) apparently healthy male sedentary college students from the same socio-economic background, having mean age of $22.4 \pm 1.02$ years, body height of $165.3 \pm 6.34 \mathrm{~cm}$ and body weight of $55.5 \pm 9.01 \mathrm{~kg}$ were recruited for the present study on the basis of random sampling from the undergraduate students of the NS Mahavidyalaya of Tripura. A computer based modified 'Stroop color word' test based on the original Stroop test (Stroop, 1935) to identify cognitive performance. After completion of stroop test in resting sitting condition participants were asked to complete Queen College Step Test to measure $\mathrm{VO}_{2}$ max. After completion of 3 mins step up exercise a recovery time of 5-15 seconds were taken for $\mathrm{VO}_{2}$ measurement and immediately after taking recovery pulse participants were asked to perform stroop III subtask to see the effect of exercise on the cognitive performance of the college students of Tripura. Results: The mean $\mathrm{VO}_{2}$ max to be found $49.1 \pm 6.25 \mathrm{ml} \cdot \mathrm{kg}^{-1} \cdot \mathrm{min}^{-1}$. The mean time to complete Stroop sub task Tasks III was found $194.3( \pm 46.34) \mathrm{sec}$. After 3 minutes step-up exercise it has been shown that the mean stroop III score was improved from $194.3( \pm 46.34)$ to $160.4( \pm 31.42)$ sec. Conclusion: It is observed in the present study that the speed of performance (i.e., stoop tasks) is improved after short term moderate exercise.

Key words: Stroop test, Cognitive attention, Step up exercise, $\mathrm{VO}_{2}$ max, Young adult
Access this article online Website:

http://nepjol.info/index.php/AJMS DOI: 10.3126/ajms.v6i6.12602

\section{INTRODUCTION}

Many animal studies have reported the beneficial influence of exercise on cognitive and brain functions. Accordingly, exercise is drawing increasing research attention as a possible lifestyle factor for improving neurocognitive functions, and preventing or delaying dementia. ${ }^{1,2}$

So far, the majority of studies have focused on the chronic effects of exercise, while studies on acute exercise effects on cognition have only started to draw growing attention. ${ }^{3}$ Recent studies provide evidence that an acute bout of moderate aerobic exercise improves cognitive performance in a choice reaction task, ${ }^{4}$ a simple reaction time task, ${ }^{5}$ as well as confliction tasks such as Erikson flanker and Stroop tasks. ${ }^{6-8}$

However, question still arises regarding type of exercise, intensity of exercise and also cognitive tasks assessment during and after exercise. ${ }^{9,10}$ Therefore, the aim of the present study was to estimate aerobic power by step up exercise used in Queens's college step test and find out the effect of step up exercise on cognitive attention with stroop test. Queens's college step test is submaximal test by which $\mathrm{VO}_{2}$ max can be predicted indirectly. It is a widely used test for young adults. 


\section{MATERIALS AND METHODS}

\section{Participants}

Twenty eight (28) apparently healthy male sedentary college students from the same socio-economic background, having mean age of $22.4 \pm 1.02$ years, body height of $165.3 \pm 6.34 \mathrm{~cm}$ and body weight of $55.5 \pm 9.01 \mathrm{~kg}$ were recruited for the present study on the basis of random sampling from the undergraduate students of the NS Mahavidyalaya of Tripura. Prior to initial testing an informed consent were taken after giving a complete explanation of the purposes, procedures and potential risks and benefits involved in the present study. They had a light breakfast 2-3 hours before the test and refrained from any energetic physical and mental activity. The participants had no history of any major diseases like asthma, cardiovascular diseases, neurological disorders, color blindness, etc and did not follow any physical conditioning programme, apart from some recreational sports.

\section{Experimental design}

Age was computed from the date of birth and date of tests. Body weight was taken using a weighing machine when boys were without shoes and wearing minimum clothes. Height was measured by an anthropometric rod. Body Mass Index (BMI) was calculated from height and weight by the following formula:

BMI $=$ Weight in kilograms divided by the square of the height in meters $\left(\mathrm{kg} / \mathrm{m}^{2}\right)$.

After taking height and weight all participants were tested individually a computer based modified 'Stroop color word' test based on the original Stroop test ${ }^{11}$ to identify cognitive performance of mental attention. Actually three subtasks (Task I, Task II \& Task III) of Stroop tests were executed. However for comparison only Sub Tasks III was considered. After completion of stroop test in resting sitting condition participants were asked to complete Queen College Step Test ${ }^{12}$ to measure $\mathrm{VO}_{2}$ max. After completion of 3 mins step up exercise a recovery of 5-15 seconds were taken for $\mathrm{VO}_{2}$ measurement and immediately after taking recovery pulse participants were asked to perform the stroop III subtask to see the effect of exercise on the cognitive performance of the college students of Tripura. All the tests were performed in the Department of the Human Physiology, NS Mahavidyalaya.

\section{Stroop test}

A computer based modified 'Strop color word' test based on the original Stroop test ${ }^{11}$ were used to check the cognitive performance. This Stroop test version consists of three subtasks (Sub Tasks I, II, III) on three slides made in the Microsoft PowerPoint 2010 version. The stimulus material for each of these subtasks is shown on a white sheet of paper that is landscape oriented with a 14 size Georgia Font). Screen was set in a normal view.

The 112 stimuli for each subtask are distributed evenly in a 14 X 8 matrix on each power point slide. The first subtask shows color words in random order (red, blue, yellow, green) printed in black ink (noncapital letters). Participants read the all words written in the slides (i.e., 112 nos) correctly as soon as possible. Participants read loudly and if any mistakes occur then he corrects himself and continues without interrupting the test. The examiner closely observed the performance of the participant and time was taken by stop watch. The Subtask II contains color words printed in an incongruous color (noncapital letters), for example, the word Red printed in blue color. Participants were asked to name the colors in which the words are written. In the Subtask III also contains color words printed in an incongruous color (noncapital letters) like subtask II, but participants were asked to read the words first and then name the colors in which the words are written.

The procedure of the tests adopted in the present study was described to all participants. However, they were not allowed to practice it before actual examination. They were seated in a adjustable computer chair and computer screen were set according to their comfortable reading distance.

Prediction of maximum oxygen uptake capacity $\left(\mathrm{VO}_{2}\right.$ max) by the queens college step test (OCT)

The step test was performed on a stool of 16.25 inches (or $41.3 \mathrm{~cm}$ ) height for a total duration of $3 \mathrm{~min}$ at the rate of $24 \mathrm{cycles} / \mathrm{min}$ which was set by a metronome. After completion of the exercise, the participants were asked to remain standing and the carotid pulse rate was measured by placing thumb on right side of carotid artery near Thyroid notch from 5 to 20 seconds of the recovery period. This 15 second pulse rate was converted into beats/min and the following equation was used to predict the maximum oxygen uptake capacity. ${ }^{12}$

$\mathrm{VO}_{2} \max (\mathrm{ml} / \mathrm{kg} / \mathrm{min})=111.33-0.42 \times$ Heart rate

\section{Data analysis}

The collected data were stored and analyzed by the statistical software (IBM SPSS Statistics for Windows, Version 21). Mean, standard deviation, minimum and maximum value were calculated. For parametric data a student ' $t$ ' test for paired observations was used to determine whether there is a significant difference between Stroop scores of before and after exercise. The level of significance was set at less than or equal to 0.05 in each analysis. 


\section{RESULTS}

Physical variables including $\mathrm{VO}_{2}$ max performances scores of the participants are given in the Table 1. The mean BMI of the participants are found to have $20.47 \pm 2.47$. On the other hand mean $\mathrm{VO}_{2}$ max was found $49.1 \pm 6.25 \mathrm{ml} \cdot \mathrm{kg}^{-1} \cdot \mathrm{min}^{-1}$. It has been shown that in the present study the mean time to complete Stroop sub task III was found $194.3( \pm 46.34)$ sec.

Comparisons of the effects of exercise on the Stroop III performance score are tabulated (Table 2). After 3 minutes step-up exercise it has been shown that the mean time required for completion stroop task was reduced from $194.3( \pm 46.34)$ to 160.4 ( \pm 31.42$)$ sec i.e., about 17 percentage reduction.

\section{DISCUSSION}

The mean BMI of the participants are found to have $20.47 \pm 2.47$ which is found within normal range as per the WHO criteria i.e. within $18-25 \mathrm{~kg} \cdot \mathrm{m}^{2} .{ }^{13}$ On the other hand mean $\mathrm{VO}_{2}$ max was found $49.1 \pm 6.25 \mathrm{ml} \cdot \mathrm{kg}^{-1} \cdot \mathrm{min}^{-1}$ which are found to some extent more as compared to another study done on the Bengali male adults, ${ }^{14}$ where it was found $39.3 \mathrm{ml} \cdot \mathrm{kg}^{-1} \cdot \mathrm{min}^{-1}$. As in the present study the $\mathrm{VO}_{2}$ was measured by indirect way through the submaximal test of queen's college step test. On the other hand Chatterjee et al (2004) ${ }^{14}$ measured $\mathrm{VO}_{2}$ by direct method. This may be the cause of higher $\mathrm{VO}_{2}$ of the present subject.

It is observed that stroop tasks were getting difficult from Task I to Task III. However, speed of performance

\begin{tabular}{|c|c|}
\hline Measures & $\begin{array}{c}\text { Mean } \pm \text { SD } \\
\text { (minimum value- maximum value) }\end{array}$ \\
\hline Age (yrs) & $20.4 \pm 1.02(18.0-22.0)$ \\
\hline Height $(\mathrm{cm})$ & $165.3 \pm 6.34(148.0-175.8)$ \\
\hline Weight (kg) & $55.5 \pm 9.01(43.0-90.0)$ \\
\hline BMI $\left(\mathrm{kg} \cdot \mathrm{m}^{2}\right)$ & $20.47 \pm 2.47(18-29.2)$ \\
\hline $\mathrm{VO}_{2} \max \left(\mathrm{ml} \cdot \mathrm{kg}^{-1} \cdot \mathrm{min}^{-1}\right)$ & $49.1 \pm 6.25(37.4-57.6)$ \\
\hline
\end{tabular}

Values are mean $\pm S D$ (minimum value- maximum value)

Table 2: Comparisons of the effect of the
exercise on the stroop performance scores
\begin{tabular}{lcc} 
Variables & Before exercise & After exercise \\
\hline Stroop III (sec) & $194.3 \pm 46.34$ & $160.4 \pm 31.42^{\star *}$ \\
& $(134.0-319.0)$ & $(99.0-240.0)$ \\
\hline
\end{tabular}

Values are mean $\pm S D$ (minimum value- maximum value); level of significance was done by the $t$ test, for paired observations; **p<0.001), Stroop III- word \& color-word score is improved after short term moderate exercise. Recent studies provide evidence that an acute bout of moderate aerobic exercise improves cognitive performance in a Stroop tasks. ${ }^{6-8,15}$

Kashihara et al, $2009^{10}$ pointed out the reasons for improved cognitive function by the exercise seem to be not only the facilitated regional cerebral blood flow and neurotransmitters in the central nervous system (CNS) but also psychological factors. However, the psycho-physiological mechanism causing inverted $\mathrm{U}$ relationship between incremental exercise and cognitive performance remains unclear. However, Yanagisawa et al., $2010^{15}$ reported a study on adult human and observed acute moderate exercise elicits increased dorsolateral prefrontal cortex activation and improves cognitive performance with stroop test.

\section{CONCLUSION}

It is observed in the present study that cognitive attention with stoop test is improved after short term sub maximal step-up exercise in young adults.

\section{ACKNOWLEDGEMENTS}

Authors are thankful to the students of the NS Mahavidyalaya, Udaipur who were the volunteer of the present study.

\section{REFERENCES}

1. Cotman CW, Berchtold NC, Christie LA. Exercise builds brain health: key roles of growth factor cascades and inflammation. Trends Neurosci 2007; 30 (9): 464-472.

2. Hillman $\mathrm{CH}$, Erickson $\mathrm{KI}$, Kramer AF. Be smart, exercise your heart: exercise effects on brain and cognition. Nat Rev Neurosci 2008; 9(1): 58-65.

3. Tomporowski PD. Effects of acute bouts of exercise on cognition. Acta Psychol (Amst) 2003; 112 (3): 297-324.

4. Chmura J, Krysztofiak H, Ziemba AW, Nazar, K, Kaciuba-Uscilko H. Psychomotor-performance during prolonged exercise above and below the blood lactate threshold. Eur J Appl Physiol Occup Physiol 1998; 77 (1-2): 77-80.

5. Collardeau M, Brisswalter J, Audiffren M. Effects of a prolonged run on simple reaction time of well-trained runners. Percept Mot Skills 2001; 93 (3): 679-689.

6. Hogervorst E, Riedel W, Jeukendrup A, Jolles J. Cognitive performance after strenuous physical exercise. Percept Mot Skills 1996; 83 (2): 479-488.

7. Kamijo K, Nishihira Y, Hatta A, Kaneda T, Wasaka T, Kida T, et al. Differential influences of exercise intensity on information processing in the central nervous system. Eur J Appl Physiol 2004; 92 (3): 305-311.

8. Kamijo K, Nishihira Y, Higashiura T, Kuroiwa K. The interactive effect of exercise intensity and task difficulty on human cognitive processing. Int J Psychophysiol 2007; 65 (2): 114-121. 
9. McMorris T. Exercise and cognition. The Open Sports Med J 2008; 2: 60-68.

10. Kashihara K, Maruyama T, Murota M, Nakahara Y. Positive effects of acute and moderate physical exercise on cognitive function. J Physiol Anthropol 2009; 28(4): 155-164.

11. Stroop JR. Studies of interference in serial verbal reactions. J Exp Psychol 1935; 18: 643-662.

12. McArdle WD, Katch FI, Pechar GS, Jacobson L, Ruck S. Reliability and Interrelationships between maximal oxygen intake, physical work capacity and step-test Scores in college women. Med Sci Sports 1972; 4: 182-186.
13. World Health Organisation. Obesity: Preventing and managing the global epidemic. Report of WHO consultation: WHO Tech Rep Ser 2000; 894: 1-253.

14. Chatterjee S, Chatterjee $\mathrm{P}$, Mukherjee S, Bandyopadhy A. Validity of Queen's college step test for use with young Indian men. Br J Sports Med 2004; 38: 289-291.

15. Yanagisawa H, Ippeita D, Tsuzuki D, Morimasa K, Masako O. Acute moderate exercise elicits increased dorsolateral prefrontal activation and improves cognitive performance with stroop test. Neuroimage 2010; 50: 1702-17010.

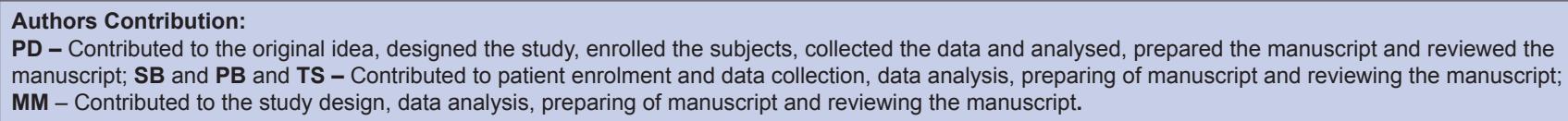

